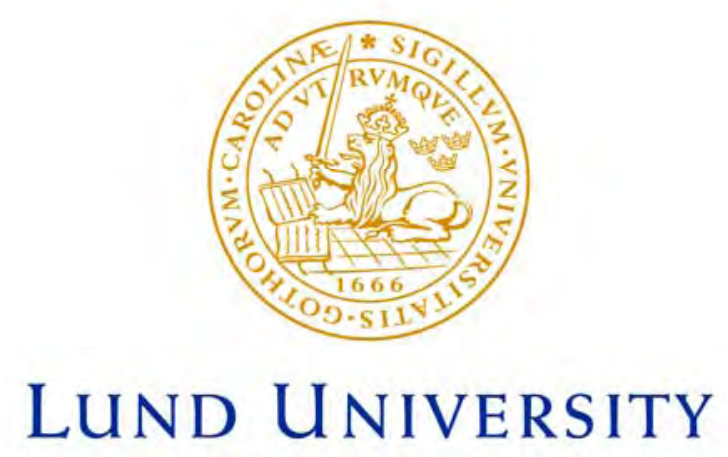

Faculty of Medicine

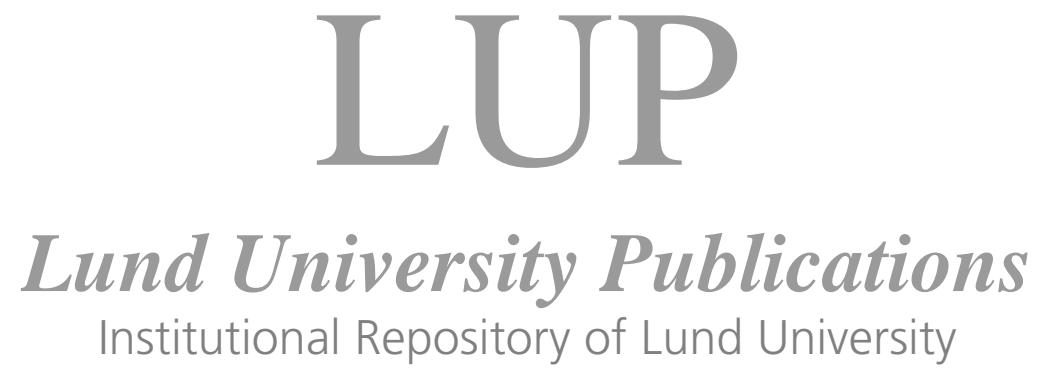

This is an author produced version of a paper published in Neuroscience. This paper has been peer-reviewed but does not include the final publisher proof-corrections or journal pagination.

Citation for the published paper:

Sajedeh Eftekhari, Christopher A Salvatore, Amy Calamari, Stefanie A Kane, Janos Tajti, Lars Edvinsson

"Differential distribution of calcitonin gene-related peptide (CGRP) and CGRP receptor components (CLR and RAMP1) in the human trigeminal ganglion."

Neuroscience, 2010, Jun 2

http://dx.doi.org/10.1016/j.neuroscience.2010.05.016

Access to the published version may require journal subscription.

Published with permission from: Elsevier 


\section{Differential distribution of calcitonin gene-related peptide (CGRP) and its receptor components in the human trigeminal ganglion}

Sajedeh Eftekhari, Msc ${ }^{1 *}$, Christopher A. Salvatore, BS ${ }^{2}$, Amy Calamari, $\mathrm{Msc}^{2}$, Stefanie A. Kane, $\mathrm{PhD}^{2}$ Janos Tajti, $\mathrm{MD}^{3}$ and Lars Edvinsson, $\mathrm{MD}^{1}$

${ }^{1}$ Department of Clinical Sciences, Division of Experimental Vascular Research, Lund University, Lund, Sweden, ${ }^{2}$ Department of Pain \& Migraine Research, Merck Research Laboratories, West Point, PA, USA, ${ }^{3}$ Department of Neurology, Albert Szent-Györgyi University Medical School, Szeged, NA, Hungary.

*Address for correspondence: Sajedeh Eftekhari, Department of Clinical Sciences, Division of Experimental Vascular Research, BMC A13, Sölvegatan 17, SE-22184 Lund, Sweden. Phone: +46 46 2220617. E-mail: Sajedeh.eftekhari@med.lu.se

Section Editor: Cellular; Dr. Constantino Sotelo. 


\section{Abbreviations}

CGRP Calcitonin gene-related peptide

CLR Calcitonin receptor-like receptor

RAMP1 Receptor activity-modifying protein 1

SP Substance P

VIP Vasoactive intestinal peptide

PACAP Pituitary adenylate cyclase activating peptide

RCP Receptor component protein

KLH Keyhole limpet haemocyanin

MBS m-Maleimidobenzoic acid N-hydroxysuccinimide ester

Ahx Aminohexanoic acid

FBS $\quad$ Fetal bovine serum

PBS Phosphate buffered-saline

BSA Bovine serum albumin

HRP Horseradish peroxidase

PFA Paraformaldehyde

Htx-Eosin Hematoxylin-Eosin

PBST Phosphate buffered-saline (PBS) containing $0.25 \%$ Triton X-100

GFAP Glial fibrillary acidic protein 
Myelin basic protein

NF

Nerve filament 


\begin{abstract}
Calcitonin gene related peptide (CGRP) has a key role in migraine and recently CGRP receptor antagonists have demonstrated clinical efficacy in the treatment of migraine. However, it remains unclear where the CGRP receptors are located within the CGRP signaling pathway in the human trigeminal system and hence the potential antagonist sites of action remain unknown. Therefore we designed a study to evaluate the localization of CGRP and its receptor components calcitonin receptor-like receptor (CLR) and receptor activity modifying protein (RAMP) 1 in the human trigeminal ganglion using immunohistochemistry and compare with that of rat.
\end{abstract}

Antibodies against purified CLR and RAMP1 proteins were produced and characterized for this study. Trigeminal ganglia were obtained at autopsy from adult subjects and sections from rat trigeminal ganglia were used to compare the immunostaining pattern. The number of cells expressing CGRP, CLR and RAMP1, respectively, were counted. In addition, the glial cells of trigeminal ganglion, particularly the satellite glial cell, were studied to understand a possible relation.

We observed immunoreactivity for CGRP, CLR and RAMP1, in the human trigeminal ganglion: 49\% of the neurons expressed CGRP, 37\% CLR and 36\% RAMP1. Co-localization of CGRP and the receptor components was rarely found. There were no CGRP immunoreactions in the glial cells; however some of the glial cells displayed CLR and RAMP1 immunoreactivity. Similar results were observed in rat trigeminal ganglia.

We report that human and rat trigeminal neurons store CGRP, CLR and RAMP1, however, CGRP and CLR/RAMP1 do not co-localize regularly but are found in separate neurons. Glial cells also contain the CGRP receptor components but not CGRP. Our results indicate, for the first time, the possibility of CGRP signaling in the human trigeminal ganglion involving both neurons and satellite glial cells. This suggests a possible site of action for the novel CGRP receptor antagonists in migraine therapy.

Keywords: trigeminocervical complex, migraine, immunohistochemistry, CLR, RAMP1. 


\section{Introduction}

Migraine is a painful, incapacitating disease affecting more than $10 \%$ of the general population. The disorder is being recognized as a fundamental neurological problem, although the primary cause of migraine attacks is still unknown (Goadsby, 2005). There has been intense research to identify signal molecules in nociceptive fibers and modulator systems associated with the trigeminal system (Edvinsson and Uddman, 2005). Signal molecules such as substance $\mathrm{P}$ (SP), neuropeptide $\mathrm{Y}$, vasoactive intestinal peptide (VIP) and pituitary adenylate cyclase activating peptide (PACAP) have been studied but the only neuronal messenger so far reliably demonstrated in acute migraine attacks is the neuropeptide calcitonin gene-related peptide (CGRP) (Goadsby et al., 1988, Durham, 2006, Edvinsson and Goadsby, 2010).

CGRP is a sensory neuropeptide consisting of 37 amino acids, stored in cranial trigeminal Cfibers and $A \delta$-fibers, and is a potent vasodilatory neuropeptide of intracranial blood vessels (Edvinsson et al., 1987, Gulbenkian et al., 2001). Several studies have revealed a correlation between migraine pain and cranial release of CGRP; it has been reported that CGRP levels in serum, cerebrospinal fluid, and saliva are elevated during migraine attacks (Goadsby et al., 1990, Goadsby and Edvinsson, 1993, Bellamy et al., 2006). A role for CGRP in migraine pathophysiology is supported by clinical evidence including: (1) CGRP infusion caused migraine in a small group of susceptible individuals (Lassen et al., 2002); and (2) CGRP receptor antagonists were shown to be effective in the acute treatment of migraine (Olesen et al., 2004, Ho et al., 2008a, Ho et al., 2008b). CGRP seems therefore to play an important role in the underlying pathology of migraine pain due to its ability to mediate vasodilatation in cerebral and meningeal vessels and to transmit nociceptive information to second order neurons within the CNS (Pietrobon, 2005).

The receptor for CGRP has been identified as a G-protein-coupled receptor of the B-subtype (Hay et al., 2008). The functional receptor consists of a complex of a seven-transmembrane spanning protein, calcitonin receptor-like receptor (CLR), a single transmembrane-spanning protein designated receptor activity modifying protein (RAMP)1 (McLatchie et al., 1998) and an intracellular protein, receptor component protein (RCP) (Evans et al., 2000). RAMP1 is involved in receptor trafficking and is required for CGRP binding to CLR, whereas the interaction of CLR with other RAMP proteins, RAMP2 or RAMP3, forms adrenomedullin receptors (McLatchie et al., 1998, Foord and Marshall, 1999, Zhang et al., 2007). 
CGRP receptor antagonists, unlike the $5 \mathrm{HT}_{1 \mathrm{~B} / 1 \mathrm{D}}$ agonists (triptans), do not constrict coronary blood vessels (Chan et al., 2010, Lynch et al., 2010) and suggest the potential for CGRP receptor antagonists to exert migraine efficacy in the absence of adverse effects on coronary vessel tone. In this context it is of considerable importance to identify the possible sites of antagonist interaction within the cranial pain systems (Edvinsson, 2008).

The trigeminal ganglion is in the center of interest for studying the expression of CGRP and its receptor components due to the activation of the trigeminovascular system during migraine attacks. The trigeminovascular system transmits signals, via second order neurons in the brain stem, to different parts of the CNS pain regions (Liu et al., 2008). Conversely, it has been hypothesized that brainstem stimulation can cause activation of the trigeminovascular system, also resulting in CGRP-dependent vasodilatation (Just et al., 2005).

The trigeminal ganglion is comprised of bipolar neurons and two types of glial cells; satellite glial cells and Schwann cells. Earlier it was believed that the main function of glial cells was that of neuronal support; however during the last decade it has been revealed that the satellite glial cells may modulate neuronal function and activity, and could therefore be a factor in migraine pathophysiology (Hanani, 2005, Dublin and Hanani, 2007, Thalakoti et al., 2007, Li et al., 2008)

Immunohistochemical studies performed on the trigeminal system have shown CGRP immunoreactivity in about $50 \%$ of the neurons of human and rat trigeminal ganglion (Tajti et al., 1999, Lennerz et al., 2008). The elegant work of Lennerz and co-workers also demonstrated CLR and RAMP1 within the rat trigeminal ganglion. However, the localization of CGRP signaling mechanisms in the human trigeminal ganglion still remains unclear.

The goals of the present study were to (1) generate and comprehensively characterize novel antibodies to human CLR and RAMP1; (2) characterize the distribution of CGRP and its receptor components, CLR and RAMP1, in the human trigeminal ganglion; (3) determine whether CGRP, CLR and RAMP1 are co-localized in the same structure; and (4) generate antibodies to rat CLR and RAMP1 to serve as a point of reference for the human mapping studies. 


\section{Experimental procedures}

\section{Generation of antibodies}

Antibodies were generated by Cambridge Research Biochemicals (Billingham, Cleveland, UK). Antigenic sequences were selected for human and rat CLR and RAMP1, purified, and coupled to keyhole limpet haemocyanin (KLH). Human CLR (acetyl-GYSHDCPSEHLNGK) was coupled to KLH using gluteraldehyde. Rat CLR (C-SIQDIENVALKPEKMYDLV), human RAMP1 (C-Ahx-QSKRTEGIV) and rat RAMP1 (C-Ahx-RSKRTEGIV) were coupled using m-Maleimidobenzoic acid N-hydroxysuccinimide ester (MBS) to KLH via an Nterminal cysteine. RAMP1 peptides contained an aminohexanoic acid (Ahx) spacer to space the short peptide away from the KLH carrier. Rabbits (human CLR, rat CLR and rat RAMP1), goat (human RAMP1), and sheep (rat CLR) were immunized with the appropriate peptide ( 2 animals per peptide). Harvest bleeds were purified by affinity chromatography. Antisera were named 3152 (rabbit anti-human CLR), 844 (goat anti-human RAMP1), 3155 (rabbit anti-rat CLR) 132 (sheep anti-rat CLR), and 3158 (rabbit anti-rat RAMP1). In blocking experiments antibodies to human and rat CLR and RAMP1 were preabsorbed by incubation with peptides used for immunization $\left(1: 100,1 \mathrm{hr},+4^{\circ} \mathrm{C}\right)$.

\section{Cell culture and generation of recombinant cell lines}

HEK293 cells were cultured in DMEM with 4.5 g/L glucose, $1 \mathrm{mM}$ sodium pyruvate and 2 mM glutamine supplemented with 10\% fetal bovine serum (FBS), 100 units/mL penicillin and $100 \mu \mathrm{g} / \mathrm{ml}$ streptomycin, and maintained at $+37^{\circ} \mathrm{C}, 5 \% \mathrm{CO}_{2}$, and $95 \%$ humidity. Cells were subcultured by treatment with $0.25 \%$ trypsin with $0.1 \%$ EDTA in HBSS.

HEK293 cells stably expressing the human CGRP (CLR/RAMP1) receptor was previously described in Salvatore et al. (2008). For transient transfections, 24 h prior to transfection HEK293 cells were seeded in $500 \mathrm{~cm}^{2}$ dishes. Transfections were performed by combining 60 $\mu \mathrm{g} /$ dish DNA with $180 \mu \mathrm{g} /$ dish Lipofectamine 2000 (Invitrogen, Carlsbad, CA). Rat CLR and RAMP1 cDNAs in the mammalian expression construct pcDNA3.1, described earlier (Mallee et al., 2002), were co-transfected in equal amounts. Transfection cocktail was added directly to the medium and the cells were harvested for membranes $48 \mathrm{~h}$ post-transfection.

\section{Membrane Preparation and Western Blotting}

Transiently and stably transfected cells were washed with phosphate-buffered saline (PBS) and harvested in ice-cold harvest buffer containing $50 \mathrm{mM}$ HEPES, $1 \mathrm{mM}$ EDTA, and Complete protease inhibitors (Roche Diagnostics, Indianapolis, IN). The cell suspension was 
disrupted with a laboratory homogenizer and centrifuged at 48,000g to isolate membranes. Membranes from untransfected HEK293 cells were prepared similary and served as a negative control.

Membranes were diluted in gel loading buffer, heated at $+70^{\circ} \mathrm{C}$ for $10 \mathrm{~min}$, and fractionated on $10 \%$ NuPAGE BisTris polyacrylamide gels (Invitrogen). Proteins were transferred to 0.2 $\mu \mathrm{m}$ nitrocellulose membranes using the iBlot transfer system according to the manufacturer's suggested protocol (Invitrogen). Blots were incubated in PBS, 1\% bovine serum albumin (BSA), $0.1 \%$ nonfat milk powder, $0.1 \%$ Tween for $1 \mathrm{hr}$ at room temperature. Blots were then incubated overnight at $+4^{\circ} \mathrm{C}$ with antibodies to CLR (1:100) or RAMP1 (1:100). After overnight incubation membranes were washed and incubated with the appropriate secondary antibody coupled to horseradish peroxidase (HRP) for $30 \mathrm{~min}$ at room temperature. Secondary antibodies were as follows: 1:40,000 goat anti-rabbit IgG HRP (SantaCruz Biotechnology, Inc., Santa Cruz, CA); 1:50,000 rabbit anti-goat IgG HRP (Millipore, Billerica, MA); and 1:100,000 rabbit anti-sheep IgG HRP (Invitrogen). Blots were then washed and immunoreactive proteins detected by chemiluminescence (Amersham ECL Plus Kit, GE Healthcare, Piscataway, NJ).

\section{Immunostaining of cell lines}

HEK293 cells stably expressing the human CGRP (CLR/RAMP1) receptor was described in previous work (Salvatore et al., 2008). Parental HEK293 and cells stably expressing the human CGRP receptor were plated on Poly-D-Lysine 8-well CultureSlides (BD Biosciences, San Jose, CA) and cultured overnight at $+37^{\circ} \mathrm{C}$ in a $\mathrm{CO}_{2}$ incubator. The following day the cells were washed with PBS and then fixed at $-20^{\circ} \mathrm{C}$ for 10 min in methanol followed by 1 min in acetone. Cells were washed a final time in PBS to remove fixative.

Cells were blocked in PBS pH 7.4 containing 2.5\% BSA and 5\% goat (hCLR, 3152; rCLR, 3155; rRAMP1, 3158) or 5\% donkey serum (hRAMP1, 844; rCLR, 132) for 30 min at room temperature. Cells were incubated with the rabbit antibody to hCLR, rCLR, and rRAMP1 (1:500), the goat antibody to hRAMP1 (1:100) or the sheep antibody to rCLR (1:100) diluted in blocking buffer for $2 \mathrm{~h}$ at room temperature. Cells were washed and incubated with Alexa Fluor $^{\circledR} 488$ goat anti-rabbit IgG (Invitrogen) for hCLR (3152), rCLR (3155) and rRAMP1 (3158); Alexa Fluor ${ }^{\circledR} 488$ donkey anti-goat IgG (Invitrogen) for hRAMP1 (844); and Alexa Fluor $^{\circledR} 488$ donkey anti-sheep IgG (Invitrogen) for rCLR (132). Secondary antibodies were diluted 1:400 in blocking buffer and incubated with the cells for $30 \mathrm{~min}$ at room temperature 
in the dark, washed in PBS, and mounted with Vectashield mounting medium containing 4',6diamidino-2-phenylindole (DAPI) (Vectashield, Vector Laboratories Inc., Burlingame CA).

\section{Human tissue samples}

Trigeminal ganglia were obtained at autopsy from adult subjects in accordance with the Szeged University Medical School guidelines for ethics in human tissue experiments and were approved by the local Hungarian Ethics Committee. Trigeminal ganglia were bilaterally removed from five subjects (4 female; 1 male) with an average age of 75 years (65-86 years). None of the subjects suffered from any central nervous system disease and the cause of death was related to heart failure, septicemia or cancer. The tissue was collected within 24 to $36 \mathrm{~h}$ after death.

The samples were immersed overnight in fixative consisting of $2 \%$ paraformaldehyde (PFA) and $0.2 \%$ picric acid in $0.1 \mathrm{~mol} / \mathrm{l}$ phosphate buffer, $\mathrm{pH}$ 7.2. After fixation, the specimens were rinsed in sucrose-enriched (10\%) Tyrode solution overnight, frozen and stored at $-80^{\circ} \mathrm{C}$. The ganglia were embedded in Tissue-Tek (Sakura Finetek, Europe), sagitally cryosectioned (12 $\mu \mathrm{m})$ and the sections stored at $-20^{\circ} \mathrm{C}$ until use.

\section{Rat tissue samples}

Trigeminal ganglia were removed from ten male Sprague-Dawley rats weighing 300-350 g (Scanbur, Stockholm, Sweden). The ganglia were placed in 4\% PFA and fixed for 2-4 h. After fixation the ganglia were rinsed in raising concentrations of sucrose in Sörensen's phosphate buffer, embedded in a gelatin medium (30\% egg albumin, 3\% gelatin in distilled water) and sagitally cryosectioned $(12 \mu \mathrm{m})$. The sections were stored at $-20^{\circ} \mathrm{C}$ until use. After sacrifice, 5 animals were kept at $+4{ }^{\circ} \mathrm{C}$ for $24 \mathrm{~h}$ before dissection of the ganglia (to mimic the autopsy situation in man). Thereafter they were treated as above.

\section{Hematoxylin-Eosin staining}

Human and rat sections were stained with Hematoxylin-Eosin (Htx-Eosin) using a standard protocol (Htx $3 \mathrm{~min}$, water rinse, Eosin $1 \mathrm{~min}$ ) for orientation and for examination of the tissue condition.

\section{Immunhistochemical studies}

Indirect immunofluorescense staining was performed to demonstrate the localization of CGRP, CLR and RAMP1 in human and rat trigeminal ganglia. The sources, characteristics and dilutions of the primary and secondary antibodies used are listed in Tables 1 and 2. In 
brief, the sections were thawed rapidly at room temperature and washed for $10 \mathrm{~min}$ in PBS pH 7.2 containing $0.25 \%$ Triton X-100 (PBST). The sections were blocked for $1 \mathrm{~h}$ in blocking solution of PBS and 5\% normal donkey or goat serum (depending on species origin of the secondary antibody). After blocking, the sections were incubated overnight at $+4^{\circ} \mathrm{C}$ for single or double immunolabelling with primary antibodies against CGRP, CLR and RAMP1; and in combination with glial fibrillary acidic protein (GFAP) and myelin basic protein (MBP), which are glial cell markers. In addition, nerve filament high molecular weight 160/200 (NF 160/200) and nerve filament low molecular weight 68 (NF 68) were used. The primary antibodies were diluted in PBST containing 1\% BSA and 3\% normal serum. After incubation with primary antibodies, sections were equilibrated to room temperature, rinsed in PBST for $3 \times 15$ min and exposed to secondary antibodies in PBST and $1 \%$ BSA for $1 \mathrm{~h}$ at room temperature. The sections were subsequently washed with PBST for 3x15 min, thereafter mounted with an anti-fading mounting medium (Vectashield, Vector Laboratories). Vectashield medium containing DAPI staining nucleuses was used on some sections.

\section{Controls and blocking peptides}

Rat trigeminal ganglia were used for comparison of the staining pattern for CGRP and its receptor components. The newly produced primary antibodies against human CLR and RAMP1 were also tested on rat trigeminal ganglion to see if a similar staining pattern was produced.

Sections of human and rat trigeminal ganglia, including rats mimicking the human postmortem situation, were treated in the same way, except for the dilutions of the primary antibodies (see Table 1). For all antibodies, omission of the primary antibody served as negative controls.

Preabsorption controls were performed with all of the CLR and RAMP1 primary antibodies. Concentrations of the antibodies were the same as described in Table 1, peptide concentrations were 100:1. The blocking peptides were resuspended in PBS and then incubated overnight in PBST containing 1\% BSA and 3\% normal serum, with or without primary antibodies, at $+4^{\circ} \mathrm{C}$. The immunostaining protocol was the same as described above. Sections incubated with antibodies alone versus blocked antibodies were compared. Similar controls were conducted for the CGRP antibody; CGRP antibody was pretreated with human CGRP $\left(10^{-4} \mathrm{M}\right.$, Tocris Bioscience, Bristol, UK). 


\section{Microscopic analysis}

HEK293 cells stable expressing the human CGRP receptor were examined and images obtained using a Zeiss Axioplan 2 fluorescence microscope with an Axiocam camera (Carl Zeiss MicroImaging, Inc., Thornwood, NY, USA). Sections were examined and images were obtained using a light- and epifluorescence microscope (Nikon 80i, Tokyo, Japan) coupled to a Nikon DS-2MV camera. Adobe Photoshop CS3 (v.8.0, Adobe Systems, Mountain View, CA) was used to visualise co-labelling by superimposing the digital images.

\section{Cell-counting}

Cell counting was performed to quantify the expression of CGRP, CLR and RAMP1 in human trigeminal ganglion. Three slides (with a minimum of three sections between each were used for measurements to avoid double-counting of cells) from each subject were stained with the respective antibody. Images were taken at a magnification at 10x.

In each image, a rectangle $\left(26.95 \mu \mathrm{m}^{2}\right)$ was placed on a homogenous stained part of the cytoplasm of immuno-positive cells. A similar procedure was undertaken in immuno-negative cells. The NIS-elements BR image analysis program (Nikon) was used to calculate the number of cells and to measure the fluorescence intensity in each area. Cells were counted and measured in 2-3 areas (depending on the size of the ganglia). Each area contained 70-100 cells and at least 30 of these cells had visible nuclei, which were the cells that were counted. The average cell count from three sections for each antibody was used for the statistical analysis. The intensity measurements were used to verify that immune-positive cells were correctly distinguished from immuno-negative cells. 


\section{Results}

\section{Specificity of CLR and RAMP1 antibodies}

The specificity of the CLR and RAMP1 antibodies were evaluated by Western blotting and immunofluorescence using stably and transiently transfected cells. Antibody 3152 (human CLR) recognized a single protein of approximately $54 \mathrm{kDa}$ in HEK293 cell membranes stably expressing the human CGRP receptor consistent with the predicted mass of the protein (Fig. 1A). Antibodies 3155 and 132 (rat CLR) recognized two proteins with molecular masses of approximately $49 \mathrm{kDa}$ and $60 \mathrm{kDa}$ in HEK293 cells transiently expressing the rat CGRP receptor (Fig. 1C,D). Human (844) and rat RAMP1 (3158) antibodies both recognized a single protein with an approximate molecular mass of $13 \mathrm{kDa}$ in human (Fig. 1B) and rat (Fig. 1E) CGRP receptor expressing cells, respectively. There were no significant signals in parental HEK293.

Immunoreactive human and rat CLR and RAMP1 were detected primarily at the plasma membrane of HEK293 cells stably expressing the human CGRP receptor (Fig. 2A,D,G,J,M). Immunoreactivity was abolished by preabsorption of antibodies with peptides used for immunization (Fig. 2B,E,H,K,N). No staining was observed in untransfected HEK293 cells (Fig. 2C,F,I,L,O).

\section{The histology of trigeminal ganglion}

Htx-Eosin stained section from human (a) and rat (b) trigeminal ganglia are depicted in Figure 3. In the human and rat trigeminal ganglia, the neurons differed in size and had lighter/darker cytoplasm. The results show that most of the cells in the trigeminal ganglion are glial cells, where the satellite cells are wrapped around the neurons. Due to age alterations, many neurons in the human material contained lipofuscin. We also observed some cell shrinkage. Aside from these changes, the human samples were considered qualitatively adequate for the immunofluorescence technique and the cell counting. Rat ganglia that were dissected $24 \mathrm{hrs}$ after sacrifice showed some cell shrinkage and splits in the tissue (Fig. 3C).

\section{Immunostaining with CLR and RAMP1 antibodies}

A detailed description of all the antibodies used in this study, including cell type or structure recognized, species in which the respective antibody was produced, dilution and source, is found in Table 1. All antibodies were applied in at least three independent staining sessions in order to validate the reproducibility of the staining results. Antibodies were generated against human and rat CLR (human 3152, rat 132 and 3155) and RAMP1 (human 844, rat 3158). For 
human trigeminal ganglion, the anti human antibodies were used; in addition they were tested on trigeminal ganglion of rat to compare the staining pattern. The anti human antibodies also worked well on rat trigeminal ganglion and displayed a similar staining pattern as seen in the human tissues (Fig. 4A). The immunoreactivity of the human anti CLR antibody was somewhat weaker compared to that of the RAMP1 antibody, in both human and rat sections. The immunoreactivity was homogenously distributed in the cytoplasm, for both anti human (Fig. 4A) and anti rat CLR and RAMP1 (Fig. 4B) antibodies, and not in the nucleus. In addition, no notable variability was observed for the localization and distribution of the respective antibody staining pattern (more described in Distribution of CGRP, CLR and RAMP1).

\section{Controls and blocking peptides}

The antibodies raised against rat CLR and rat RAMP1 utilized the antigenic sequences identified previously (Cottrell et al., 2005), and allowed comparison between rat and human localization experiments. In the study presented here we compared the findings on the human material with trigeminal ganglia of rat; they were by and large very similar. The primary antibodies for CGRP and the receptor components worked well in both human and rat trigeminal ganglion (Fig. 4A,B). As an additional control for the human material, rat ganglia were removed 24 hrs after sacrifice. The CGRP antibody and the newly produced receptor component antibodies were tested on these postmortem controls and showed the same immunoreactivity as visualized in the human and in the "normal" rat material (data shown in supplementary file). The morphology of the cells was somewhat poorer, as seen in the HtxEosin staining. The negative controls (omission of primary antibody) showed no reactivity, except for the lipofuscin autofluorescence in the neurons, and in connective tissue of human trigeminal ganglion. There was no staining with preabsorbed CLR or RAMP1 antibodies, using their respective blocking peptides (Fig. 4C). The CGRP immunoreactivity was abolished if pretreated with an excess of unlabeled CGRP (data not shown).

\section{Quantitative analysis}

We counted cells that stained positive for CGRP and the receptor components in five human trigeminal ganglia (Table 3). Immunoreactivity for CGRP was found in $49 \%$ of the neurons (positive cells/total number of cells; 459/946), CLR in 37\% (193/521) and RAMP1 in 36\% $(151 / 422)$ of the neurons. 
We also measured the fluorescence intensity to assess the probability of selecting cells as positive or negative, respectively. The cells selected as positive or negative varied within its group approximately by 20 on the gray scale (range 0-256). The mean difference between positive and negative cells varied with the primary antibody used. The CLR and RAMP1 antibodies showed the least difference (approx 20) whereas the CGRP antibody displayed the most (approx 60), indicating that our method for cell-counting was reliable. Cells that were judged as outliers were removed from the analysis.

\section{Distribution of CGRP, CLR and RAMP1}

We observed immunoreactivity for CGRP, CLR and RAMP1, respectively, in the trigeminal neurons (Fig. 4A). Expression of CGRP was predominantly localized to smaller neurons, whereas CLR and RAMP1 immunoreactivity was expressed primarily in larger neurons. The CGRP immunoreactivity was detected in the cytoplasm in a granular-like staining pattern (Fig. 5A). In addition, we observed CGRP immunoreactivity in fibers proximal to the cell bodies (Fig. 5A). We also observed fibers positive for CLR and RAMP1, although the CGRP positive fibers seemed thinner than those positive for CLR and RAMP1. CGRP did not colocalize with NF 160/200 or NF 68 (Fig. 5B), while the receptor components were expressed in thicker fibers and co-localized with NF 160/200 (Fig. 5C).

Double immunolabeling was performed to investigate co-localization of CLR and RAMP1 in the human samples (Fig. 6A). It was shown that in most cases co-localization occurred between the receptor components, suggesting the presence of the CGRP receptor. However, there were exceptions; figure 6A shows a neuron expressing both RAMP1 and CLR while another neuron only expressed RAMP1.

We also evaluated if CGRP and its receptor components were expressed in the same neuron. As shown above we found co-localization of CLR and RAMP1 in most instances. The combination of CGRP with CLR (Fig. 6B) or RAMP1 (Fig. 6C) was uncommon. Occasional neurons (very few) showed co-localization and then only in the small to medium sized cells (Fig. 6C).

Besides neurons within the human trigeminal ganglion, we observed that some satellite glial cells were positive for CLR and RAMP1 (Fig. 7A) but not for CGRP. The neurons are usually 
surrounded by a string of satellite glial cells; neurons negative or positive for the receptor components where sometimes immunoreactivite for CLR and RAMP1 in the adjacent satellite glial cells. In rat trigeminal ganglion, similar results were observed (Fig. 7A). Also, the glial cell marker GFAP co-localized with RAMP1 (Fig. 7B). Double immunostaining could only be performed with the GFAP antibody in combination with the RAMP1 antibody due to the host species of the antibodies. Therefore, the combination of CLR and GFAP was studied with the sheep anti-rat CLR antibody in rat trigeminal ganglion (Fig. 7C).

Schwann cells surrounding nerve fibers were studied with the MBP marker in human crosssectioned nerve (Fig. 8A). In rat trigeminal ganglion, both cross-sectioned and length sectioned nerve fibers could be studied (Fig. 8B). Immunoreactivity was never observed for CGRP or the receptor components CLR or RAMP1 in the Schwann cells. In cross-sectioned nerves, the receptor components were found to co-localize with the marker for NF 160/200 (Fig. 8C) but not with MBP. 


\section{Discussion}

The aim of the present study was to identify CGRP and its receptor components within the human trigeminal ganglion compared with the rat and to evaluate morphologically their relationship using immunohistochemistry. For this purpose, we developed new antibodies against human and rat CLR and RAMP1 and characterized these in detail. The study has, for the first time, demonstrated the detailed distribution and quantification of CGRP receptor components in the human trigeminal ganglion. The CGRP receptor is localized to both neurons (mainly large) and satellite glial cells (surrounding neurons), while CGRP is only expressed in the neurons of small to medium size and these lack CGRP receptor components. The CGRP immunoreactivity was found in about $50 \%$ of the neurons of a small to medium size while the receptor component proteins, CLR and RAMP1, were seen to co-localize in large sized neurons (which were CGRP negative). This suggests that if CGRP is released within the ganglion, then intraganglionic CGRP may act on satellite glial cells and on large sized neurons. We also observed differences in thickness of the fibers positive for CGRP and the receptor components. In nerve fibers within the trigeminal ganglion, the receptor components were expressed in the neuronal processes but not in the surrounding Schwann cells.

\section{Methodology and technical considerations}

The use of human material is valuable since results from such studies may contribute to our knowledge about the physiology and pathology in human disorders involving the trigeminal system. However, there are some difficulties and limitations when working with human tissue. Human trigeminal ganglia were obtained from adult subjects and the tissue samples were collected within 24 to $36 \mathrm{~h}$ of autopsy. The time lapse between death and postmortem examination allows a series of reactions and autolysis processes to initiate/take place in the tissue. This could cause problems in the immunohistochemial method, such as changes in epitopes, leakage of macrophages and leukocytes from the vessels, unspecific and/or high background staining in the tissue. Due to the relatively high age of the subjects, lipofuscin is accumulated in the neurons, causing auto-fluorescence. Also, the exact orientation of the ganglia is missing and therefore regional variations in CGRP and receptor distribution can not be determined. The hematoxylin-eosin stained material revealed well-preserved human ganglia that were adequate for the immunofluorescence technique and cell counting. We performed cell-counting on human trigeminal ganglia for CGRP and the receptor components. Due to the auto-fluorescence in the neurons we decided to perform this task manually, where 
we counted and measured intensity for positive and negative cells. This was conducted in order to verify that immune-positive cells were correctly distinguished from immuno-negative cells. Use of confocal microscope would probably improve our work; however, this was not within the scope of the present study.

\section{Characterization of CLR and RAMP1 antibodies}

In general it is difficult to find antibodies that work specifically in human material, therefore antibodies against human CLR and RAMP1 were produced. Additionally, antibodies against rat CLR and RAMP1 were also generated. The specificity of the antibodies raised against human and rat CLR and RAMP1 was confirmed in HEK293 cells stably expressing the human CGRP receptor. Immunoreactive CLR and RAMP1 were detected at the plasma membrane in stably transfected cells, but no immunostaining was detected in untransfected HEK293 cells. Additionally, preabsorption of the primary antibodies with the peptides used for immunization abolished the staining of cell lines. The specificity of CLR and RAMP1 antibodies was also confirmed by Western blotting. Human and rat CLR antibodies recognized proteins consistent with the molecular weight of CLR. The human CLR antibody recognized a single protein whereas the rat CLR antibody recognized two proteins, most likely representing different glycosylated states of the protein. Human and rat RAMP1 antibodies recognized a single protein of $\sim 13 \mathrm{kDa}$, which is slightly lower than the predicted mass of $17 \mathrm{kDa}$. Although slightly lower in mass than predicted, both the human and rat RAMP1 antibodies recognize the same molecular weight protein in stably (human) and transiently expressing (rat) cell lines, therefore this does not appear to be an artifact. Additionally, there were no detectable signals in parental HEK293 cells indicating the signal is a direct result of CGRP receptor expression.

The newly produced primary antibodies against CGRP receptor components worked well for immunohistochemistry on the human and rat trigeminal ganglia. The anti human CLR antibody showed a somewhat weaker staining in both human and rat sections compared to the RAMP1 antibody. Overall the primary antibodies displayed similar localization and distribution of the staining pattern in human and rat trigeminal ganglia. Preabsorption with the blocking peptides resulted in no immunoreactivity for the antibodies against CLR and RAMP1 in the human or rat trigeminal ganglia, which shows that these antibodies are specific for the epitope they are raised against. Similar controls were conducted for the CGRP 
antibody; exogenous CGRP blocked the immunoreactions as could be expected and verified before (Tajti et al., 2001, Uddman et al., 2002).

\section{The distribution of CGRP and the receptor components}

CGRP has been shown to be expressed in trigeminal nerve endings, which densely innervate the cerebral blood vessels (Uddman et al., 1985, Edvinsson et al., 1987). Several studies have shown that the trigeminovascular system has an important role in migraine pathophysiology. Stimulation of the trigeminal ganglion both in humans and in animals resulted in release of CGRP and elevation of CGRP in the external jugular vein followed by vasodilatation (Goadsby et al., 1988, Limmroth et al., 2001). Taken together, the release of CGRP from trigeminal neurons seems to play an important role in migraine pathophysiology, in both initiating and sustaining migraine attacks. Previous studies have shown both protein and mRNA levels of CGRP within human and rat trigeminal ganglia (Edvinsson et al., 1998, Tajti et al., 1999, Hou et al., 2001, Li et al., 2008).

The localization of the CGRP receptor elements in the trigeminovascular system has not been fully clarified to date (Lennerz et al., 2008). We have previously reported the expression of CLR and RAMP1 on smooth muscle cells in human cerebral and meningeal arteries (Oliver et al., 2002, Edvinsson et al., 2010) and of CGRP receptor mRNA in human cerebral vessels and trigeminal ganglion (Edvinsson et al., 1997).

In the present study the distribution of CGRP, CLR and RAMP1 within the human and rat trigeminal ganglia was demonstrated. We observed that neurons positive for CGRP were mostly negative for the receptor components CLR and RAMP1. Almost 50\% of human trigeminal neurons expressed CGRP, which is in agreement with previous studies in man (Tajti et al., 1999) and rat (Ma et al., 2001, Lennerz et al., 2008). Expression of CLR and RAMP1 was seen in approximately $40 \%$ of the neurons. In a study on rat trigeminal ganglion, it was reported that CLR was more frequently expressed than RAMP1 in the neurons (Lennerz et al., 2008). The dissimilarity between these results and ours could be due to several factors such as the use of different primary antibodies, cell-counting method or differences between human and rat trigeminal ganglia. However, our in parallel study of the rat trigeminal ganglion revealed similar results as we report for the human trigeminal ganglion.

We observed that the CGRP-positive cells were mostly small- to medium sized while the receptor components were expressed in the larger trigeminal neurons. We decided not to 
measure the cell diameters due to cell shrinkage in the human material. Different size of the neurons was also observed with Htx-eosin staining, where the dye-uptake in the cytoplasm also differed. The histology of neurons in the human trigeminal ganglion has been described before (Krastev et al., 2007) where they classified human trigeminal neurons into different groups according to their shape, size and light or dark cytoplasm. Here we present a variation in size between neurons expressing CGRP and those that store the receptor components, the function of this differential distribution remains to be clarified. The CGRP immunoreactivity displayed a granular-like staining pattern in the neuronal cell bodies, which could be due to the localization of CGRP in the endoplasmatic reticulum. In addition, thin "pearl-like" staining of the fibers was observed. This type of granular staining pattern of CGRP in human trigeminal neurons has been described previously (Quartu et al., 1992).

In addition to the difference in cell-size of neurons positive for CGRP, CLR and RAMP1, we found a difference in thickness of the fibers positive for CGRP and the receptor components; this was confirmed using nerve filament antibodies for different molecular weights. It was clearly shown that CGRP was expressed in thinner fibers, which did not co-localize with the marker for smaller diameter neurofilaments. It is tempting to speculate that the thin CGRP positive fibers belong to the $\mathrm{C}$-fibers and project to the lamina $\mathrm{I} / \mathrm{II}$ in the trigeminal complex of the brainstem while the CGRP negative fibers are A $\delta$-fibers that contain CLR/RAMP1 project to lamina III/IV (Liu et al., 2004, 2008). This hypothesis may unravel with studies of the trigeminal complex using the present novel antibodies.

In order to verify neurons expressing CGRP and the receptor components, doubleimmunolabelling was performed. The results revealed that co-localization between the neuropeptide and its receptor component occurs rarely, suggesting low presence of putative auto-receptors (CGRP receptors on cells storing CGRP) within the human and rat trigeminal ganglion. The combination of CLR and RAMP1 was considerably more frequent on CGRPnegative neurons; whereas neurons expressing only a single receptor component were rarely observed. This might indicate that there exist situations when the CGRP receptor is not expressed as a functional receptor, however, this needs to be further evaluated. Our results are in agreement with those of Lennerz and colleagues (2008), who showed that a low percent of the trigeminal neurons express CGRP and RAMP1 together. They found that the combination of CGRP and CLR was more frequent; however a functional CGRP receptor requires RAMP1 expression. As described earlier, CLR can interact with other RAMP proteins, RAMP2 or RAMP3 to form adrenomedullin receptors (McLatchie et al., 1998, Foord and Marshall, 1999, 
Zhang et al., 2007). This could explain the finding of cells being immuno-positive for CLR but not for RAMP1. However, the functional role of RAMP1 only positive neurons remains unclear.

The CGRP receptor has long been proposed as target for antimigraine drugs (Edvinsson, 2004, Doods et al., 2007, Durham, 2008). Today the CGRP receptor antagonist telcagepant is being developed (Paone et al., 2007, Edvinsson and Linde, 2010). Clinical studies conducted to date have found telcagepant to be superior to placebo in reducing the pain and symptoms associated with acute migraine (Ho et al., 2008a, Ho et al., 2008b). Results from our study indicate that the human trigeminal ganglion could be one possible target for CGRP receptor antagonists.

\section{The glial cells}

The physiological function of the satellite glial cells within the trigeminal ganglion is not yet fully understood. However, recent studies show that neuron-glial signaling may occur via gap junctions, and the release of CGRP within the ganglion could further stimulate the release of nitric oxide and pro-inflammatory cytokines from the satellite glial cells (Thalakoti et al., 2007, Li et al., 2008, Capuano et al., 2009, Vause and Durham, 2009). We observed that the CGRP receptor components could be located on satellite glial cells within their cytoplasm. This observation was confirmed with the co-localization of a glial cell marker and the distinct organizational pattern around the neurons. Studies performed on rat trigeminal ganglion also demonstrated the expression of the CGRP receptor components on satellite glial cells (Lennerz et al., 2008, Li et al., 2008). The function of this localization needs to evaluated, however expression of receptors in satellite glial cells suggest that they can receive signals from CGRP positive neurons and potentially respond to activate local inflammatory signals. Also, it could be hypothesized that CGRP receptor antagonists could have an effect on the satellite glial cells and thereby preventing the release of inflammatory cytokines and nitric oxide.

We found no immunoreactivity for CGRP or the receptor components in Schwann cells. In cross-sectioned nerves, it was clearly shown that CLR and RAMP1 were expressed in neuronal processes, rather than Schwann cells. This suggests that these cells originate from the large neurons and belong to the A $\delta$-fibers. 


\section{Concluding remarks}

The neuropeptide CGRP is implicated in the underlying pathology of migraine and the CGRP receptor has long been regarded as a useful target for the development of novel antimigraine therapies. Using immunohistochemistry and new antibodies specifically recognizing CLR and RAMP1, we studied in detail CGRP and its receptor components in the human trigeminal ganglion and compared with that of rat. Our study contributes to a better understanding of CGRP signaling in the trigeminal ganglion. In summary, we found that small to medium sized neurons express CGRP and not CLR and RAMP1, while larger neurons contain only CLR and RAMP1, suggesting that the trigeminal ganglion could be a possible site of action for CGRP receptor antagonists. Interestingly, the receptor components were also located on satellite glial cells and neuronal fibers. Further efforts are essential to evaluate the role of trigeminal ganglion and satellite glial cells in the pathology of migraine. 


\section{Figure legends}

\section{Figure 1}

Western blot analysis of human and rat CGRP receptors expressed in transfected cells. Detection of human CLR (A), human RAMP1 (B), rat CLR (C,D), and rat RAMP1 (E) in cells stably or transiently expressing the human and rat CGRP receptor, respectively. Lysates of HEK293 CLR/RAMP1 expressing cells (Lane 1) or parental HEK293 cells (Lane 2) were separated by SDS-PAGE and analyzed via Western blotting.

\section{Figure 2}

Detection of CLR and RAMP1 in HEK293 cells stably transfected with the human CGRP receptor. Panels on the top row are transfected cells without preabsorption, center row panels are corresponding preabsorption controls, and bottom row panels are untransfected control cells. All antibodies detect CLR (A, 3152; G, 3155; J, 132) and RAMP1 (D, 844; M, 3158) predominantly at the plasma membrane. Preabsorption controls and control cells for each antibody are in the center (B, 3152; E, 844; H, 3155; K, 132; N, 3158) and bottom panels (C, 3152; F, 844; I, 3155; L, 132; O, 3158), respectively. There was no detectable staining in the preabsorption controls or the untransfected cells, consistent with a specific signal for all antibodies.

\section{Figure 3}

Hematoxylin -Eosin staining of human $(\mathbf{A})$ and rat $(\mathbf{B}, \mathbf{C})$ trigeminal ganglia. The neurons differ in size and dye-uptake in the cytoplasm in both species. The majority of the cells in trigeminal ganglion are glial cells, where the satellite glial cells surround the neurons (arrows and insert). Many neurons (asterisk) in the human material contain lipofuscin (autofluorescent). To mimic the human postmortem situation, rat ganglia were removed 24 hrs after sacrifice (C), showing cell shrinkage and splits in the tissue.

\section{Figure 4}


A) Expression of CGRP and its receptor components, CLR and RAMP1, in human trigeminal ganglion using anti-human receptor antibodies. Rat trigeminal ganglia (controls) showed the same staining pattern. Homogenous staining is observed in the cytoplasm of positive cells (arrows) with spared nucleus. The anti CLR antibody displays some nonspecific staining of the nucleus. CGRP is mostly expressed in small to medium sized neurons, while CLR and RAMP1 are expressed in larger neurons. Note CGRP positive fibers (asterisk). B) Immunostaining of rat trigeminal ganglion with the anti-rat antibodies against CLR and RAMP1. Positive cells are marked with arrows. C) Anti-human CLR and RAMP1 antibodies versus pre-absorbtion with their respective blocking peptides. Large arrows indicate positive neurons and neuronal processes in cross-sectioned nerve. No positive immunoreactivity is observed in the neurons or in cross-sectioned nerve when the blocking peptides are used (small arrows). In the negative controls (use of only the secondary antibodies, FITC for CLR and Alexa 488 for RAMP1), no reactivity is observed, except for the lipofuscin autofluorescence in the neurons and connective tissue (asterisks) of human trigeminal ganglion.

\section{Figure 5}

CGRP staining of human trigeminal ganglion (A and $\mathbf{B}$ ). The staining displays a granular-like pattern in the nucleus and positive thin fibers proximal to the cell bodies (arrows). Higher magnification shows the staining pattern in detail including "pearl-like” fibers (A). Doublestaining of CGRP and NF 68 (B) shows that the CGRP fibers (arrows) do not co-localize with fibers of thicker size. However, expression of the receptor components is found in thicker neurons. Figure C displays the expression of CLR and NF 160/200 (arrows) and their colocalization in the merged picture. Similar results are observed in trigeminal ganglion of rat (arrows).

\section{Figure 6}

Double staining of human trigeminal ganglia (anti-human antibodies) and rat ganglia. A) RAMP1 and CLR. Large arrows indicate RAMP1 and CLR positive neurons and their colocalization in the merged picture. A neuron only expressing RAMP1 is identified with a small arrow. In rat trigeminal ganglion, it is observed that the receptor components co-localize in most cases (arrow), especially in neurons of a larger size. Observe the co-localization of CLR and RAMP1 in the fibers (asterisk). Double staining of CLR and CGRP (B) and RAMP1 
and CGRP (C) show that the receptor components are mostly expressed in larger neurons (large arrow) while CGRP is expressed in smaller-sized neurons (small arrows). Colocalization occurs rarely, and then only in smaller neurons (arrowhead). Similar results are shown in the rat sections, where fibers positive for CGRP do not co-localize with fibers positive for the receptor components (asterisks).

\section{Figure 7}

Demonstration of CLR and RAMP1 expression in satellite glial cells of human trigeminal ganglia (anti-human antibodies) and rat ganglia, including nuclear DAPI staining (A). The satellite glial cells surrounding the neurons (arrows) appear to express CLR and RAMP1. The DAPI staining shows that the receptor components are expressed in the cytoplasm of the satellite glial cells. Note that the surrounded neurons can be negative or positive for the receptor components. Similar observations are found in rat (lower panel). Expression of RAMP1 in glial cells is also confirmed with the marker for GFAP (B), double-staining shows clear co-localization (arrows). Co-localization of CLR and GFAP was performed in rat (C), which also shows co-localization (arrows). DAPI is used in the merged picture to clarify the orientation of satellite glial cells.

\section{Figure 8}

RAMP1 (anti-human antibody) and MBP double staining in human trigeminal ganglion (A). In cross-sectioned nerve it is shown that RAMP1 is expressed in neuronal processes (large arrows) and not in the Schwann cells, studied with the MBP marker, (arrowheads). At higher magnification (insert in the merged picture) it is clear that RAMP1 expression does not colocalize with MBP. Similar results were obtained in rat sections (B), where cross-sectioned and length-sectioned nerves display CLR and RAMP1 expression in neuronal processes (arrows) and not Schwann cells (arrowheads). C) CLR and RAMP1 double-staining with NF 160/200. In cross-sectioned nerve of human trigeminal ganglion, the receptor components are found to co-localize with NF 160/200 (arrows). Inserts show higher magnification. DAPI, staining nuclei, is used in the merged pictures (blue). 


\section{Figure for supplementary file}

A) Immunostaining of CGRP and the receptor components, CLR and RAMP1, in rat trigeminal ganglia dissected 24 hrs after sacrifice. The staining pattern is similar to that seen in human and the "normal” rat material. Cell shrinkage and nuclear condensation are found. Arrows point at positive neurons.

B) Anti-rat CLR and RAMP1 antibodies versus pre-absorbtion with their respective blocking peptides. Large arrows point at positive neurons. No positive immunoreactivity is shown in the neurons when the blocking peptides are used (small arrows). 


\section{Acknowledgements}

Thanks to Professor Karin Warfvinge and Warfvinge Science Support for assistance and valuable comments on the manuscript. 


\section{References}

Bellamy JL, Cady RK, Durham PL (2006) Salivary levels of CGRP and VIP in rhinosinusitis and migraine patients. Headache 46:24-33.

Capuano A, De Corato A, Lisi L, Tringali G, Navarra P, Dello Russo C (2009) Proinflammatory-activated trigeminal satellite cells promote neuronal sensitization: relevance for migraine pathology. Mol Pain 5:43.

Chan KY, Edvinsson L, Eftekhari S, Kimblad PO, Kane SA, Lynch J, Hargreaves R, Vries R, Garrelds IM, Bogaerdt AV, Danser AH, MaassenVanDenBrink A (2010) Characterization of the CGRP receptor antagonist telcagepant (MK-0974) in human isolated coronary arteries. J Pharmacol Exp Ther submitted.

Cottrell GS, Roosterman D, Marvizon JC, Song B, Wick E, Pikios S, Wong H, Berthelier C, Tang Y, Sternini C, Bunnett NW, Grady EF (2005) Localization of calcitonin receptor-like receptor and receptor activity modifying protein 1 in enteric neurons, dorsal root ganglia, and the spinal cord of the rat. J Comp Neurol 490:239-255.

Doods H, Arndt K, Rudolf K, Just S (2007) CGRP antagonists: unravelling the role of CGRP in migraine. Trends Pharmacol Sci 28:580-587.

Dublin P, Hanani M (2007) Satellite glial cells in sensory ganglia: their possible contribution to inflammatory pain. Brain Behav Immun 21:592-598.

Durham PL (2006) Calcitonin gene-related peptide (CGRP) and migraine. Headache 46 Suppl 1:S3-8.

Durham PL (2008) Inhibition of calcitonin gene-related peptide function: a promising strategy for treating migraine. Headache 48:1269-1275.

Edvinsson L (2004) Blockade of CGRP receptors in the intracranial vasculature: a new target in the treatment of headache. Cephalalgia 24:611-622.

Edvinsson L (2008) CGRP blockers in migraine therapy: where do they act? Br J Pharmacol 155:967-969.

Edvinsson L, Cantera L, Jansen-Olesen I, Uddman R (1997) Expression of calcitonin generelated peptide1 receptor mRNA in human trigeminal ganglia and cerebral arteries. Neurosci Lett 229:209-211.

Edvinsson L, Chan KY, Eftekhari S, Nilsson E, Vries R, Säveland H, Dirven C, Danser AH, MaassenVanDenBrink A (2010) Effect of the calcitonin gene-related peptide (CGRP) receptor antagonist telcagepant in human cranial arteries. Cephalalgia in press

Edvinsson L, Ekman R, Jansen I, McCulloch J, Uddman R (1987) Calcitonin gene-related peptide and cerebral blood vessels: distribution and vasomotor effects. J Cereb Blood Flow Metab 7:720-728.

Edvinsson L, Goadsby P (2010) CGRP receptor antagonism in the treatment of migraine: where did that come from? Nat Rev Neuro in press

Edvinsson L, Linde M (2010) New drugs in migraine treatment: telcagepant and topiramate. Lancet review in press

Edvinsson L, Mulder H, Goadsby PJ, Uddman R (1998) Calcitonin gene-related peptide and nitric oxide in the trigeminal ganglion: cerebral vasodilatation from trigeminal nerve stimulation involves mainly calcitonin gene-related peptide. J Auton Nerv Syst 70:1522.

Edvinsson L, Uddman R (2005) Neurobiology in primary headaches. Brain Res Brain Res Rev 48:438-456.

Evans BN, Rosenblatt MI, Mnayer LO, Oliver KR, Dickerson IM (2000) CGRP-RCP, a novel protein required for signal transduction at calcitonin gene-related peptide and adrenomedullin receptors. J Biol Chem 275:31438-31443. 
Foord SM, Marshall FH (1999) RAMPs: accessory proteins for seven transmembrane domain receptors. Trends Pharmacol Sci 20:184-187.

Goadsby PJ (2005) Migraine pathophysiology. Headache 45 Suppl 1:S14-24.

Goadsby PJ, Edvinsson L (1993) The trigeminovascular system and migraine: studies characterizing cerebrovascular and neuropeptide changes seen in humans and cats. Ann Neurol 33:48-56.

Goadsby PJ, Edvinsson L, Ekman R (1988) Release of vasoactive peptides in the extracerebral circulation of humans and the cat during activation of the trigeminovascular system. Ann Neurol 23:193-196.

Goadsby PJ, Edvinsson L, Ekman R (1990) Vasoactive peptide release in the extracerebral circulation of humans during migraine headache. Ann Neurol 28:183-187.

Gulbenkian S, Uddman R, Edvinsson L (2001) Neuronal messengers in the human cerebral circulation. Peptides 22:995-1007.

Hanani M (2005) Satellite glial cells in sensory ganglia: from form to function. Brain Res Brain Res Rev 48:457-476.

Hay DL, Poyner DR, Quirion R (2008) International Union of Pharmacology. LXIX. Status of the calcitonin gene-related peptide subtype 2 receptor. Pharmacol Rev 60:143-145.

Ho TW, Ferrari MD, Dodick DW, Galet V, Kost J, Fan X, Leibensperger H, Froman S, Assaid C, Lines C, Koppen H, Winner PK (2008a) Efficacy and tolerability of MK0974 (telcagepant), a new oral antagonist of calcitonin gene-related peptide receptor, compared with zolmitriptan for acute migraine: a randomised, placebo-controlled, parallel-treatment trial. Lancet 372:2115-2123.

Ho TW, Mannix LK, Fan X, Assaid C, Furtek C, Jones CJ, Lines CR, Rapoport AM (2008b) Randomized controlled trial of an oral CGRP receptor antagonist, MK-0974, in acute treatment of migraine. Neurology 70:1304-1312.

Hou M, Kanje M, Longmore J, Tajti J, Uddman R, Edvinsson L (2001) 5-HT(1B) and 5$\mathrm{HT}(1 \mathrm{D})$ receptors in the human trigeminal ganglion: co-localization with calcitonin gene-related peptide, substance P and nitric oxide synthase. Brain Res 909:112-120.

Just S, Arndt K, Doods H (2005) The role of CGRP and nicotinic receptors in centrally evoked facial blood flow changes. Neurosci Lett 381:120-124.

Krastev D, Paloff D, Hinova-Palova A, Ovtscharoff W (2007) Light-microscopic structure of trigeminal ganglion in humans. J IMAB, book 1 111-113.

Lassen LH, Haderslev PA, Jacobsen VB, Iversen HK, Sperling B, Olesen J (2002) CGRP may play a causative role in migraine. Cephalalgia 22:54-61.

Lennerz JK, Ruhle V, Ceppa EP, Neuhuber WL, Bunnett NW, Grady EF, Messlinger K (2008) Calcitonin receptor-like receptor (CLR), receptor activity-modifying protein 1 (RAMP1), and calcitonin gene-related peptide (CGRP) immunoreactivity in the rat trigeminovascular system: differences between peripheral and central CGRP receptor distribution. J Comp Neurol 507:1277-1299.

Li J, Vause CV, Durham PL (2008) Calcitonin gene-related peptide stimulation of nitric oxide synthesis and release from trigeminal ganglion glial cells. Brain Res 1196:22-32.

Limmroth V, Katsarava Z, Liedert B, Guehring H, Schmitz K, Diener HC, Michel MC (2001) An in vivo rat model to study calcitonin gene related peptide release following activation of the trigeminal vascular system. Pain 92:101-106.

Liu Y, Broman J, Edvinsson L (2004) Central projections of sensory innervation of the rat superior sagittal sinus. Neuroscience 129:431-437.

Liu Y, Broman J, Edvinsson L (2008) Central projections of the sensory innervation of the rat middle meningeal artery. Brain Res 1208:103-110.

Lynch J, Regan C, Edvinsson L, Hargreaves R, Kane S (2010) Comparison of the vasoconstrictor effects of the calcitonin gene-related peptide (CGRP) receptor 
antagonist telcagepant (MK-0974) and zolmitriptan in human isolated coronary arteries. J Cardiovasc Pharmacol in press

Ma QP, Hill R, Sirinathsinghji D (2001) Colocalization of CGRP with 5-HT1B/1D receptors and substance $P$ in trigeminal ganglion neurons in rats. Eur J Neurosci 13:2099-2104.

Mallee JJ, Salvatore CA, LeBourdelles B, Oliver KR, Longmore J, Koblan KS, Kane SA (2002) Receptor activity-modifying protein 1 determines the species selectivity of non-peptide CGRP receptor antagonists. J Biol Chem 277:14294-14298.

McLatchie LM, Fraser NJ, Main MJ, Wise A, Brown J, Thompson N, Solari R, Lee MG, Foord SM (1998) RAMPs regulate the transport and ligand specificity of the calcitonin-receptor-like receptor. Nature 393:333-339.

Olesen J, Diener HC, Husstedt IW, Goadsby PJ, Hall D, Meier U, Pollentier S, Lesko LM (2004) Calcitonin gene-related peptide receptor antagonist BIBN 4096 BS for the acute treatment of migraine. N Engl J Med 350:1104-1110.

Oliver KR, Wainwright A, Edvinsson L, Pickard JD, Hill RG (2002) Immunohistochemical localization of calcitonin receptor-like receptor and receptor activity-modifying proteins in the human cerebral vasculature. J Cereb Blood Flow Metab 22:620-629.

Paone DV, Shaw AW, Nguyen DN, Burgey CS, Deng JZ, Kane SA, Koblan KS, Salvatore CA, Mosser SD, Johnston VK, Wong BK, Miller-Stein CM, Hershey JC, Graham SL, Vacca JP, Williams TM (2007) Potent, orally bioavailable calcitonin gene-related peptide receptor antagonists for the treatment of migraine: discovery of $\mathrm{N}-[(3 \mathrm{R}, 6 \mathrm{~S})-6-$ (2,3-difluorophenyl)-2-oxo-1- (2,2,2-trifluoroethyl)azepan-3-yl]-4- $\quad$ (2-oxo-2,3dihydro-1H-imidazo[4,5-b]pyridin- 1-yl)piperidine-1-carboxamide (MK-0974). J Med Chem 50:5564-5567.

Pietrobon D (2005) Migraine: new molecular mechanisms. Neuroscientist 11:373-386.

Quartu M, Diaz G, Floris A, Lai ML, Priestley JV, Del Fiacco M (1992) Calcitonin generelated peptide in the human trigeminal sensory system at developmental and adult life stages: immunohistochemistry, neuronal morphometry and coexistence with substance P. J Chem Neuroanat 5:143-157.

Salvatore CA, Hershey JC, Corcoran HA, Fay JF, Johnston VK, Moore EL, Mosser SD, Burgey CS, Paone DV, Shaw AW, Graham SL, Vacca JP, Williams TM, Koblan KS, Kane SA (2008) Pharmacological characterization of MK-0974 [N-[(3R,6S)-6-(2,3difluorophenyl)-2-oxo-1-(2,2,2-trifluoroethyl)azepan-3- yl]-4-(2-oxo-2,3-dihydro-1Himidazo[4,5-b]pyridin-1-yl)piperidine-1-carbox amide], a potent and orally active calcitonin gene-related peptide receptor antagonist for the treatment of migraine. $\mathrm{J}$ Pharmacol Exp Ther 324:416-421.

Tajti J, Uddman R, Edvinsson L (2001) Neuropeptide localization in the "migraine generator" region of the human brainstem. Cephalalgia 21:96-101.

Tajti J, Uddman R, Moller S, Sundler F, Edvinsson L (1999) Messenger molecules and receptor mRNA in the human trigeminal ganglion. J Auton Nerv Syst 76:176-183.

Thalakoti S, Patil VV, Damodaram S, Vause CV, Langford LE, Freeman SE, Durham PL (2007) Neuron-glia signaling in trigeminal ganglion: implications for migraine pathology. Headache 47:1008-1023; discussion 1024-1005.

Uddman R, Edvinsson L, Ekman R, Kingman T, McCulloch J (1985) Innervation of the feline cerebral vasculature by nerve fibers containing calcitonin gene-related peptide: trigeminal origin and co-existence with substance P. Neurosci Lett 62:131-136.

Uddman R, Tajti J, Hou M, Sundler F, Edvinsson L (2002) Neuropeptide expression in the human trigeminal nucleus caudalis and in the cervical spinal cord C1 and C2. Cephalalgia 22:112-116. 
Vause CV, Durham PL (2009) CGRP stimulation of iNOS and NO release from trigeminal ganglion glial cells involves mitogen-activated protein kinase pathways. J Neurochem 110:811-821.

Zhang Z, Winborn CS, Marquez de Prado B, Russo AF (2007) Sensitization of calcitonin gene-related peptide receptors by receptor activity-modifying protein-1 in the trigeminal ganglion. J Neurosci 27:2693-2703. 
Table 1. Details on primary antibodies used for immunohistochemistry

\begin{tabular}{|c|c|c|c|c|}
\hline Name and product code & Host & Dilution & Detects & Supplier \\
\hline $\begin{array}{l}\text { Calcitonin receptor-like } \\
\text { receptor (CLR) } 3152\end{array}$ & Rabbit & $1: 500^{\mathrm{a}}$ & C-terminal of human CLR & Merck \& Co., Inc \\
\hline CLR 3155 & Rabbit & $1: 500$ & C-terminal of rat CLR & Merck \& Co., Inc \\
\hline CLR 132 & Sheep & $1: 100$ & C-terminal of rat CLR & Merck \& Co., Inc \\
\hline $\begin{array}{l}\text { Receptor activity modifying } \\
\text { protein (RAMP1) } 844\end{array}$ & Goat & $1: 100$ & $\begin{array}{l}\text { C-terminal of human } \\
\text { RAMP1 }\end{array}$ & Merck \& Co., Inc \\
\hline RAMP1 3158 & Rabbit & $1: 500$ & C-terminal of rat RAMP1 & Merck \& Co., Inc \\
\hline $\begin{array}{l}\text { Calcitonon gene related } \\
\text { peptide (CGRP), B47-1 }\end{array}$ & Rabbit & $1: 1600$ & rat CGRP & $\begin{array}{l}\text { Europroxima; Arnhem, The } \\
\text { Netherlands }\end{array}$ \\
\hline CGRP, ab81887 $7^{b}$ & Mouse & $1: 100$ & rat $\alpha$-CGRP & Abcam; UK \\
\hline $\begin{array}{l}\text { Neurofilament } 68 \text { (NF 68) } \\
\text { N5139 }\end{array}$ & Mouse & $1: 800$ & $\begin{array}{l}\text { Neurofilament of molecular } \\
\text { weight } 68 \mathrm{kDa}\end{array}$ & Sigma; St Louis, MO \\
\hline NF $160 / 200$ & Mouse & $1: 800$ & $\begin{array}{l}\text { Neurofilament of molecular } \\
\text { weight } 160 \text { and } 200 \mathrm{kDa}\end{array}$ & Sigma; St Louis, MO \\
\hline $\begin{array}{l}\text { Glial fibrillary acidic protein } \\
\text { (GFAP) }\end{array}$ & Rabbit & $1: 1500$ & Cytoskeleton in glial cells & Dako; Copenhagen, Denmark \\
\hline $\begin{array}{l}\text { Myelin basic protein (MBP) } \\
\text { A0623 }\end{array}$ & Rabbit & 1:200 & Myelin, Schwann cells & Dako; Copenhagen, Denmark \\
\hline
\end{tabular}

${ }^{a}$ Cross-reacts with rat receptor at 1:100 dilution.

${ }^{\mathrm{b}}$ Used for double-staining. 
Table 2. Secondary antibodies used for immunohistochemistry

\begin{tabular}{llll}
\hline Conjugate and host & Against & Dilution & Supplier \\
\hline FITC (goat) & anti-rabbit & $1: 100$ & Cayman Chemical, Ann Arbor,MI \\
Dylight 488 (donkey) & anti-sheep & $1: 200$ & Jackson Immuoresearch, West Grove, PA \\
Alexa 488 (donkey) & anti-goat & $1: 400$ & Invitrogen, La Jolla, CA \\
Texas-Red (donkey) & anti-mouse & $1: 200$ & Jackson Immuoresearch, West Grove, PA \\
Texas-Red (donkey) & anti-rabbit & $1: 200$ & Jackson Immuoresearch, West Grove, PA \\
\hline
\end{tabular}


Table 3. Cell-counting in human trigeminal ganglia

\begin{tabular}{|c|c|c|c|}
\hline No & CGRP & CLR & RAMP1 \\
\hline 1. & $49 \%$ & $37 \%$ & $29 \%$ \\
2. & $48 \%$ & $30 \%$ & $47 \%$ \\
3. & $47 \%$ & $64 \%$ & $30 \%$ \\
4. & $53 \%$ & $23 \%$ & $35 \%$ \\
5. & $47 \%$ & $39 \%$ & $41 \%$ \\
\hline Mean & $\mathbf{4 9 \%}$ & $\mathbf{3 7 \%}$ & $\mathbf{3 6} \%$ \\
\hline
\end{tabular}

Table showing cell-counting in human trigeminal ganglia. CGRP, CLR and RAMP1 positive cells were counted in five human subjects. 


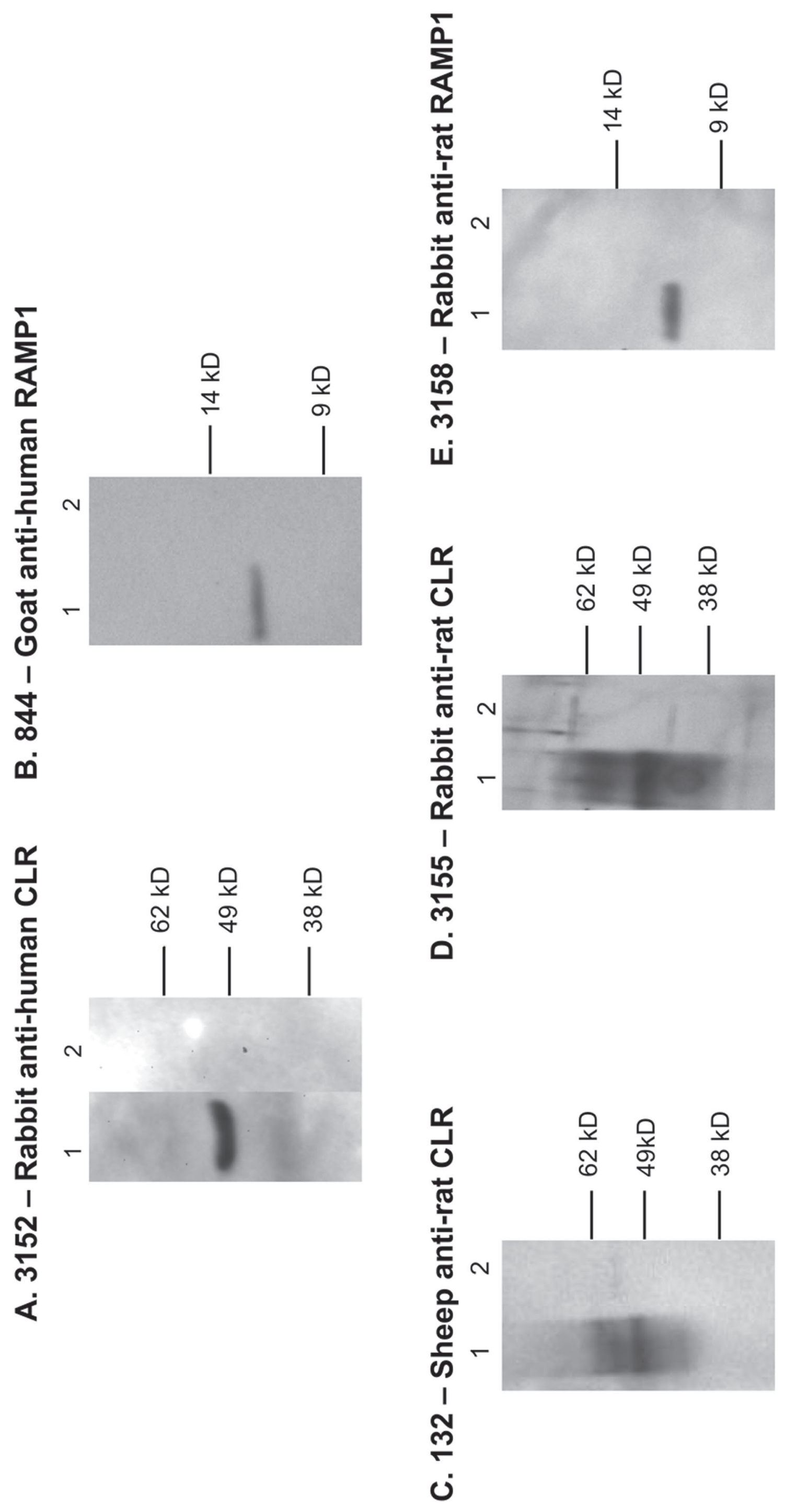



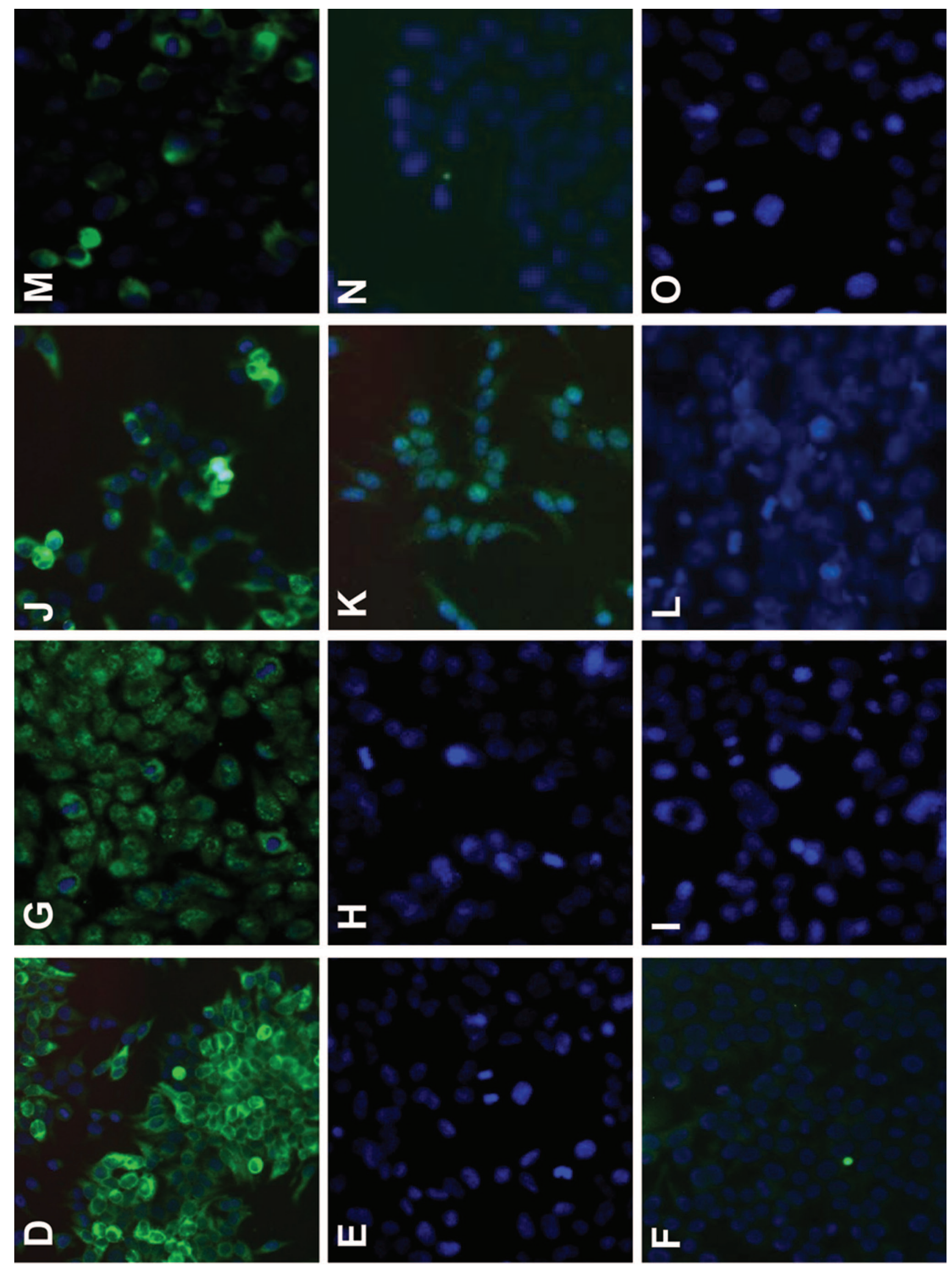

U

ㄴ.

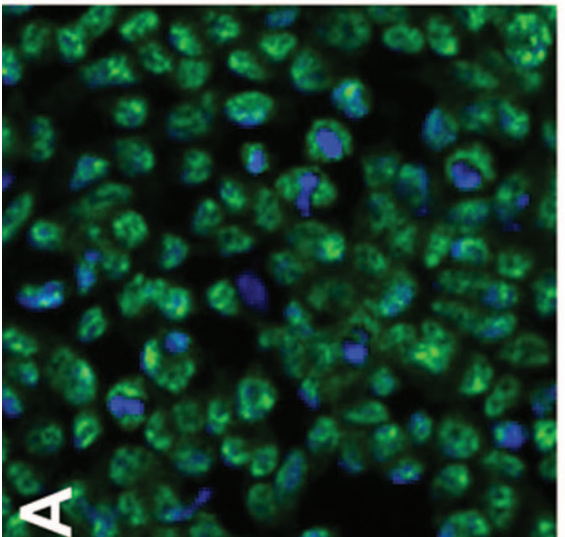

4 

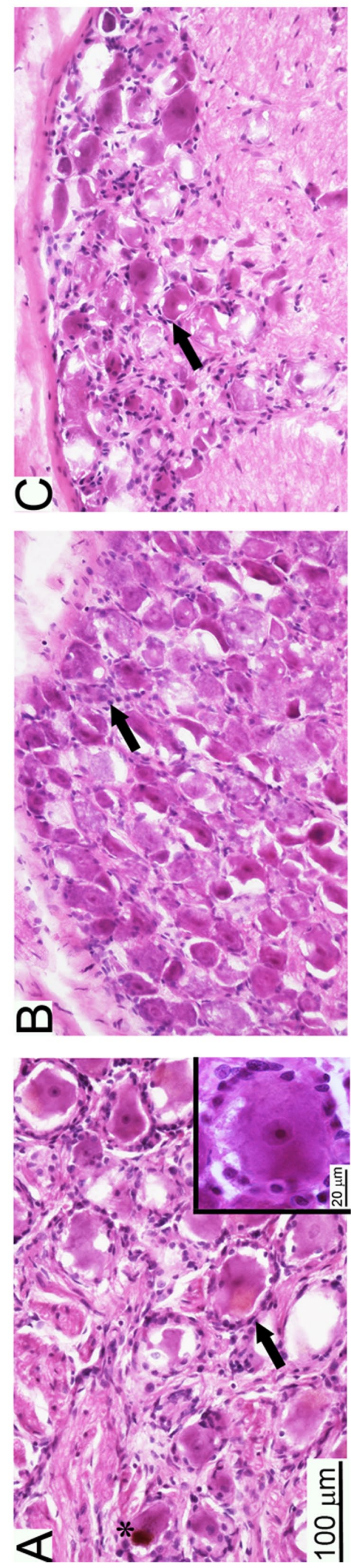
A) Distribution of CGRP CLR and RAMP1
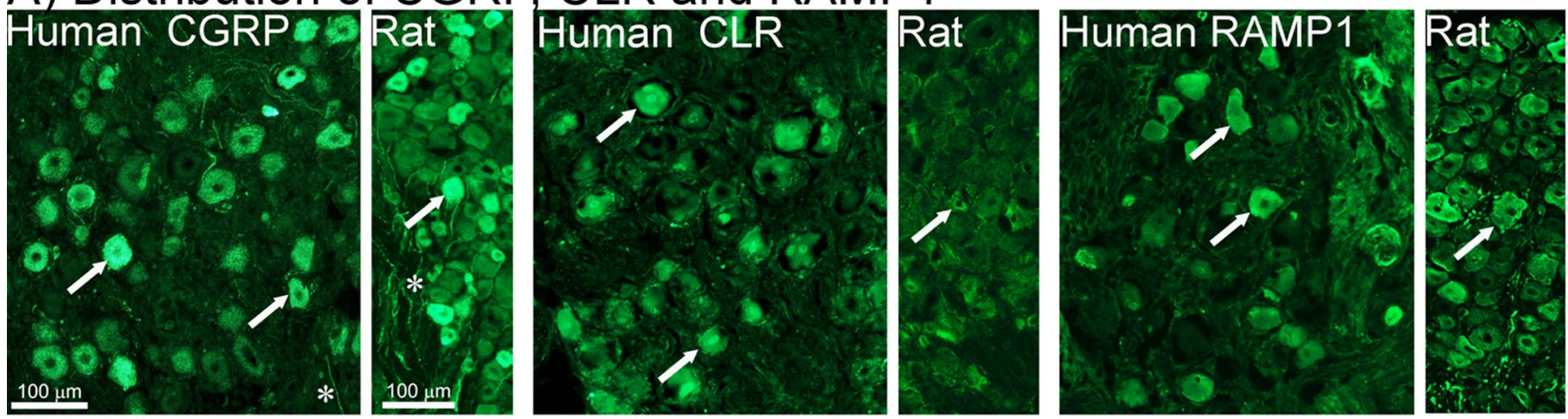

B) Anti-rat antibodies
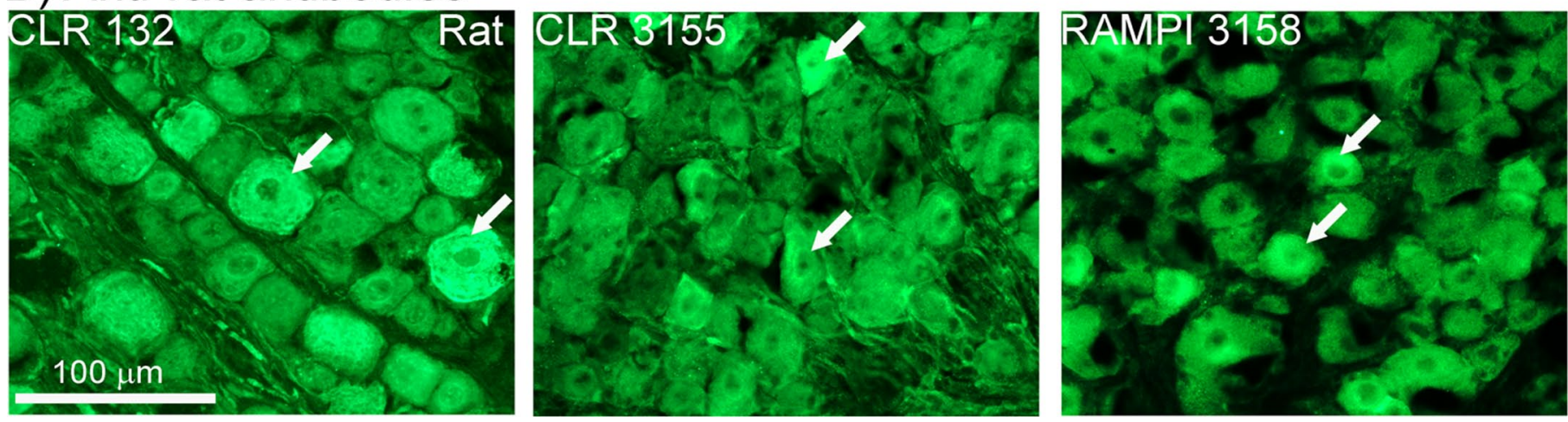

C) Blocking peptides and negative controls
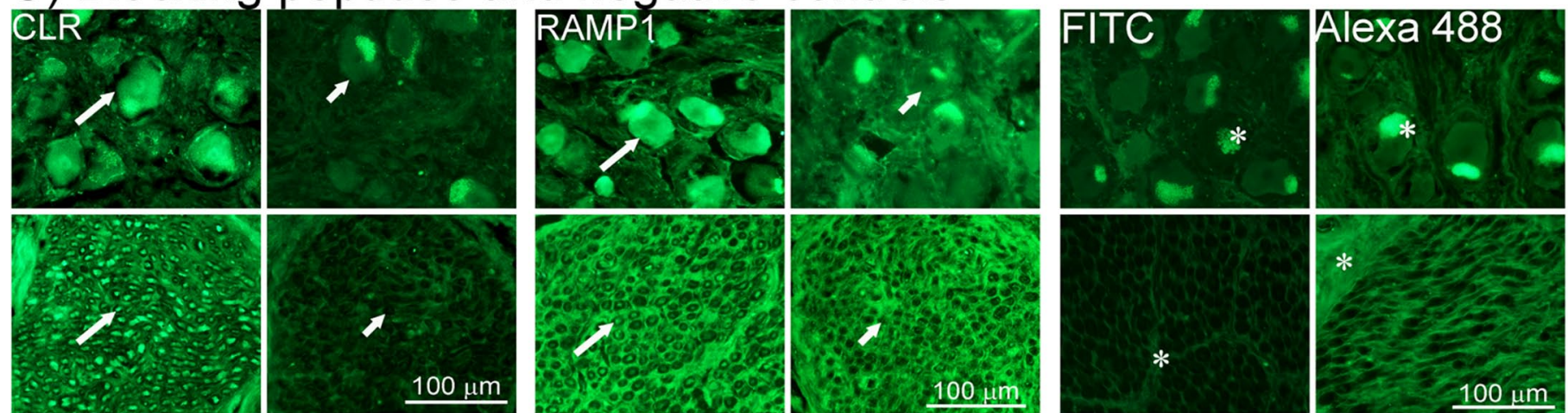

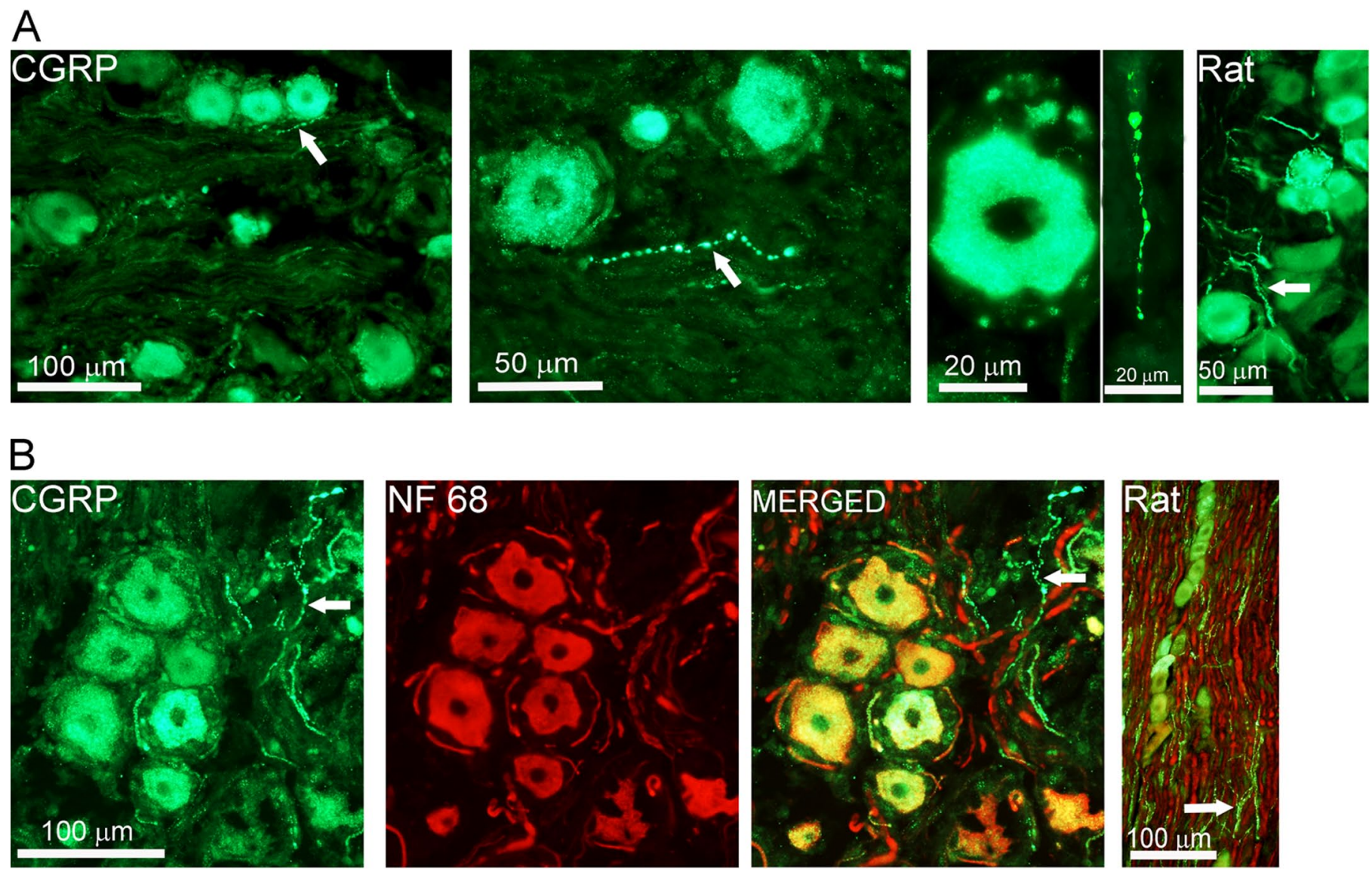

C
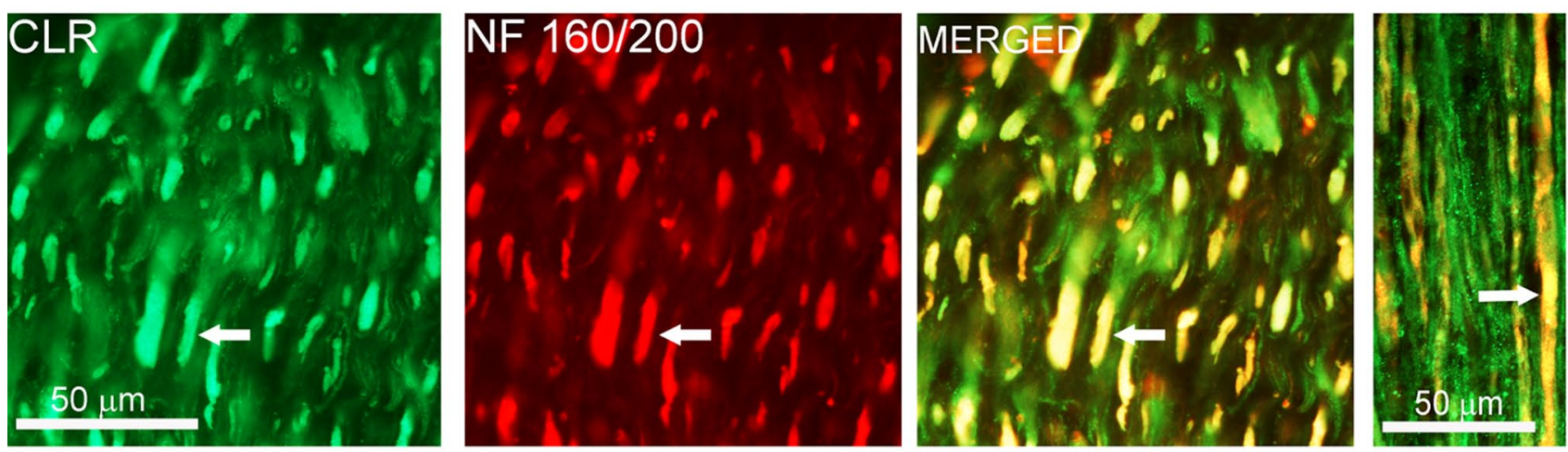

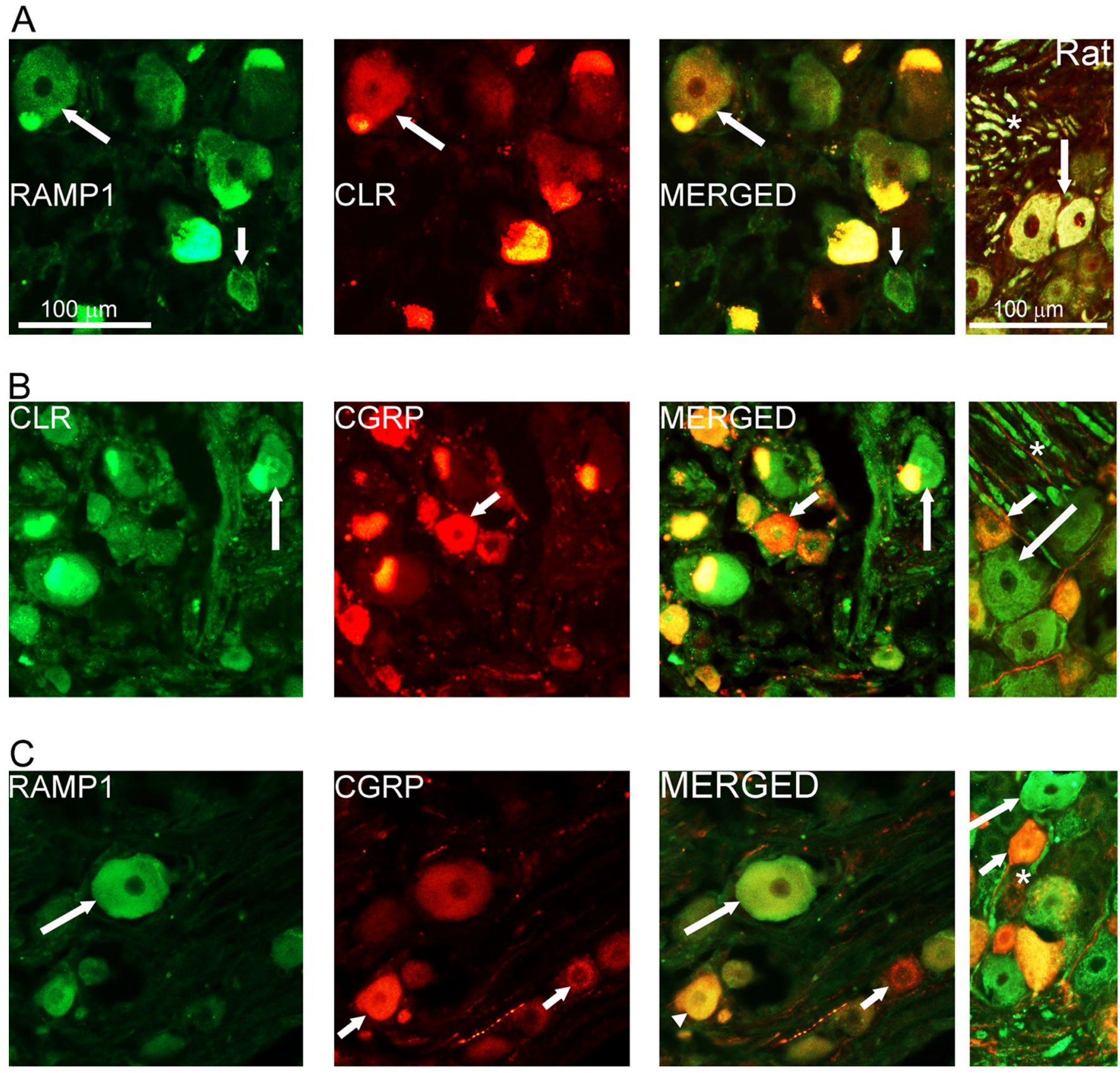

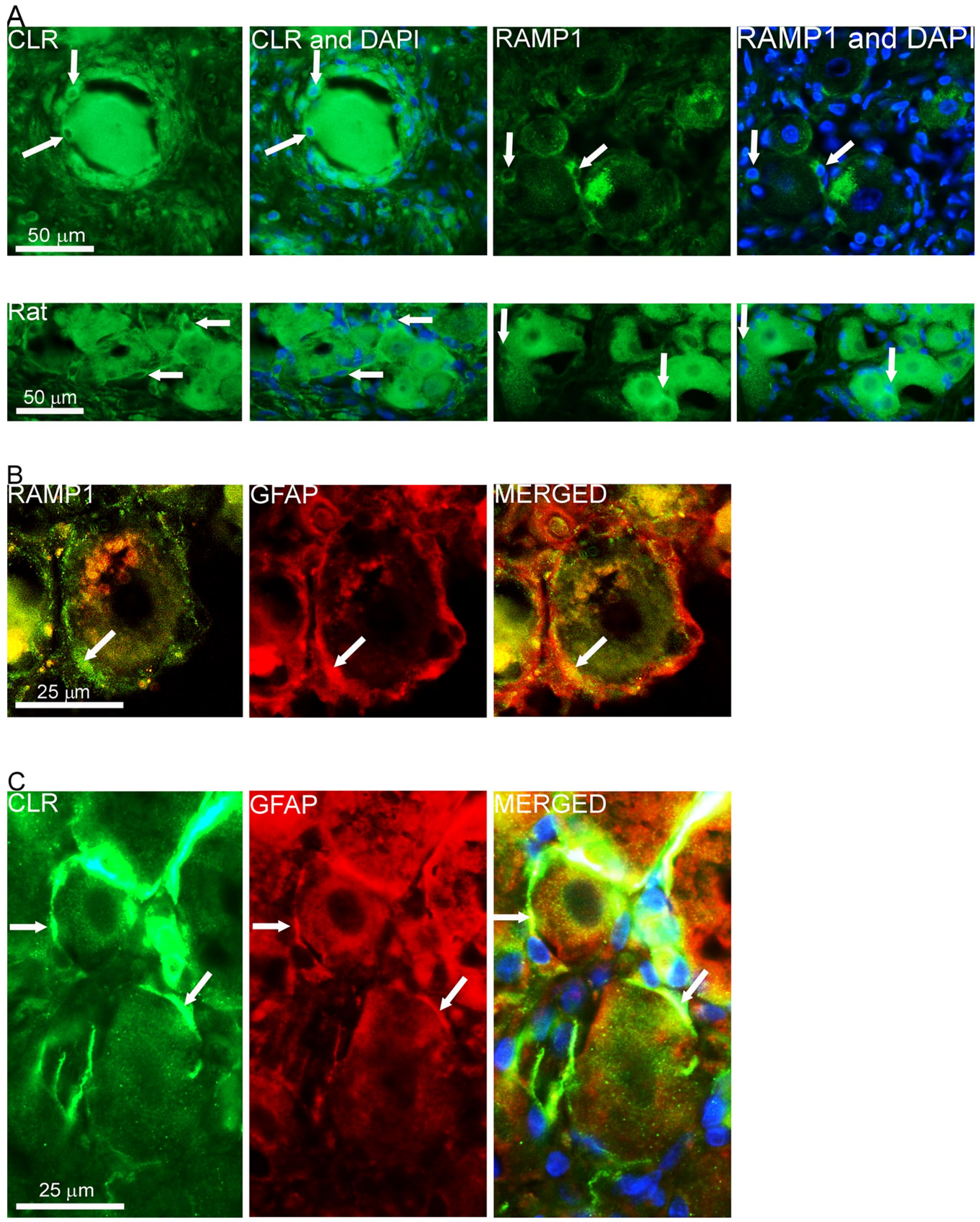

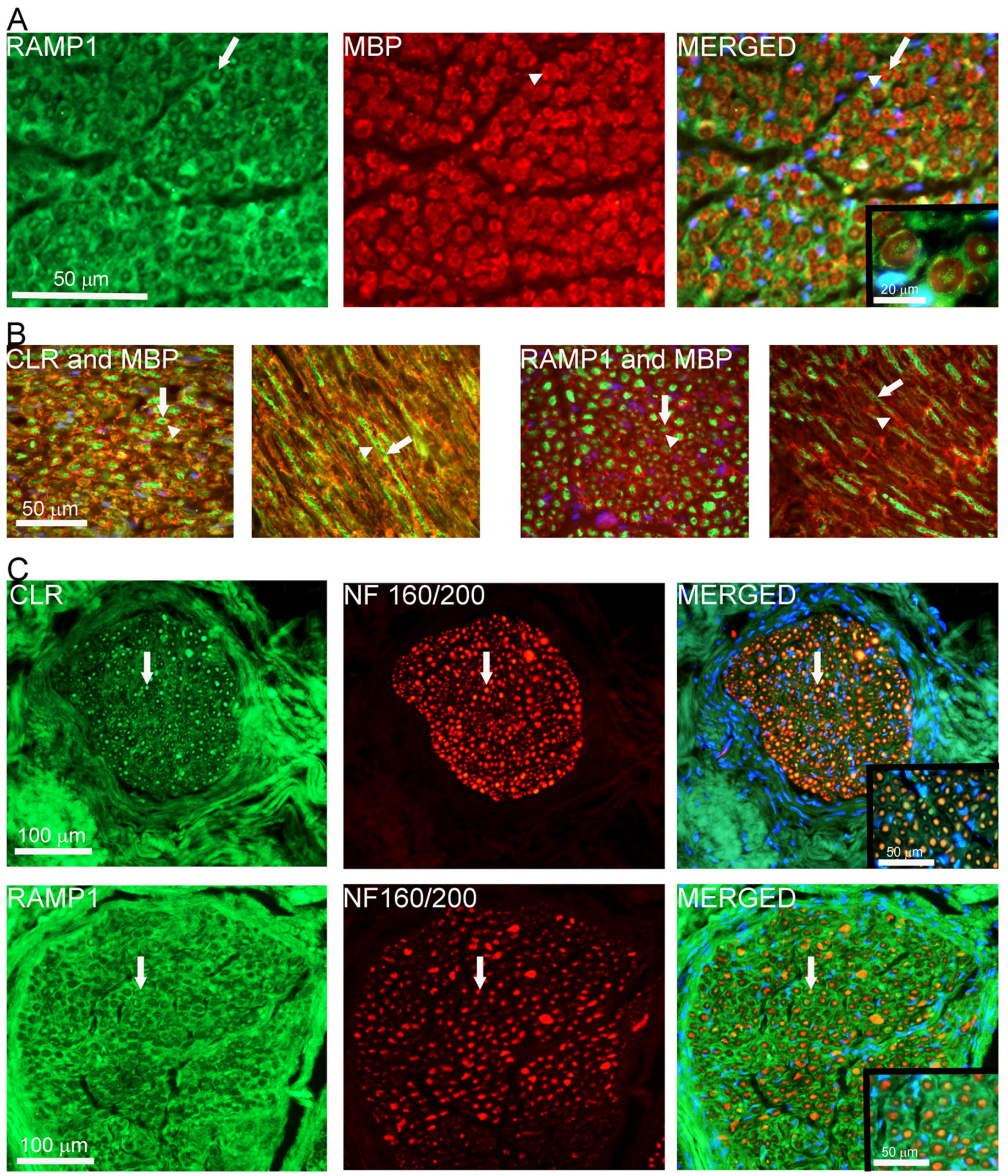

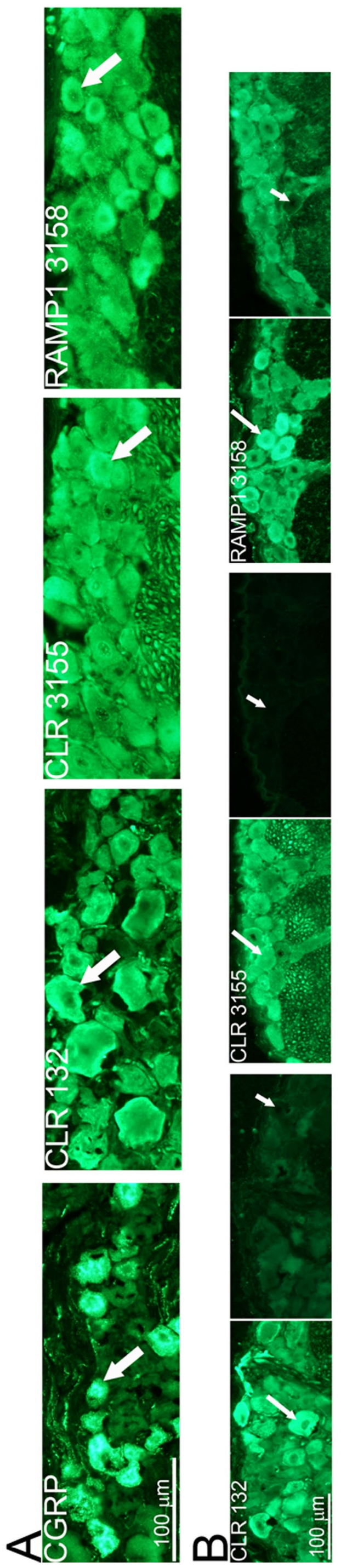